Reserch Atide

\title{
INTERVENTION THROUGH INTERNET TO IMPROVE HEALTH COGNITIVE FACTORS IN ADOLESCENTS
}

\section{Guevara-Valtier, MC*1., Paz-Morales, MA¹., Gutiérrez-Valverde, JM1., Ruvalcaba- Rodríguez-MD ${ }^{1}$, Vega-Grimaldo, MA $^{2}$ and Pacheco-Pérez, LA $^{3}$}

\author{
1,2School of Nursing. University Autonomous of Nuevo Leon. Mexico \\ ${ }^{3}$ School of Nursing and Nutrition. University Autonomous of Chihuahua. Mexico
}

DOI: http://dx.doi.org/10.24327/ijrsr.2017.0805.0288

\section{ARTICLE INFO}

\section{Article History:}

Received $18^{\text {th }}$ February, 2017

Received in revised form $10^{\text {th }}$

March, 2017

Accepted 06 ${ }^{\text {th }}$ April, 2017

Published online $28^{\text {th }}$ May, 2017

Key Words:

Internet, Adolescent, Cognitive Factors

\begin{abstract}
Objective: To evaluate the effect of an internet intervention to improve cognitive health factors ("Lifestyle perception, self-efficacy and health status in adolescents"). Methodology: The pre experimental test-retest design was done with a sample of 250 adolescents. The intervention was named "S@lud y Más". It was programmed to be completed in eight weeks. The contents were offered in six topics (Nutrition, physical activity, stress management, health responsibility, spiritual growth and interpersonal relationships). Results: It was differenced regarding to the first and second measures in the lifestyle indicators, perception of health status and self-efficacy increased significantly at the end of the intervention $(p<.05)$. Conclusion: The intervention by internet was effective to improve cognitive factors in the adolescents.
\end{abstract}

Copyright (C) Guevara-Valtier, MC et al, 2017, this is an open-access article distributed under the terms of the Creative Commons Attribution License, which permits unrestricted use, distribution and reproduction in any medium, provided the original work is properly cited.

\section{INTRODUCTION}

According to the National Institute of Statistics, Geography and Informatics (INEGI, 2015), there are more than 29.9 million people between 15 and 29 years of age in Mexico. This situation not only represents a demographic problem, but a public health problem as well, specifically in adolescents. The overpopulation of this age group and the behaviors that tend to manifest in this stage of life establish unhealthy life styles that generate nontransmissible diseases and, consequently, a premature death (WHO, 2015).

In other words, $35 \%$ of adolescents suffer from overweight or obesity, which represents about $6,325,131$ individuals between 12 and 19 years of age. In relation to this the most relevant risk factors that contribute to the excessive body weight gain in adolescents are primarily a sedentary life style or lack of physical activity, like exercise (Díaz et al, 2015, Ten et al, 2016), primarily influenced by the excessive number of hours spent in front of a TV (Katzmarzyk et al, 2015, Laurson et al, 2015) or electronic entertainment devices, together with hypercaloric eating habits where the family has a significant influence (He et al, 2015, Flattum et al, 2015). The previous overview, all this is known as an obesogenic environment (Miqueleiz et al, 2015), which together with biological factors like certain hormones that stimulate hunger and satiety, the baby's weight at birth and genetic load, condition the excess of body fat in adolescents (Walker et al, 1987) and metabolic problems (González et al, 2015., Landgraf et al, 2015). Consequently, on the one hand, non-transmissible diseases like diabetes, hypertension and metabolic syndrome are increasingly more common among adolescents and, on the other hand, obesity has also been associated with psychosomatic symptoms like depression and anxiety levels (Landgraf et al, 2015, Mühlig et al, 2016).

In light of this context, it becomes necessary to reinforce the health sector policies and programs to fight this problem, since according to epidemiologic indicators, they have not been effective. Traditionally, the indicators to fight unhealthy life styles present laboratory data and anthropometric measurements. However, in order to complement the biological balance, it is necessary to strengthen the cognitive aspects that favor good health practices in the population. More specifically, it is necessary to strengthen the "Lifestyle's Perception in Adolescents (LPA)", improve the "Perception of the State of Health" (PSOH), and "Self-Efficacy (SE)".

It is here where it becomes important to use theoretical models in order to understand how the interventions of the Health 
System can have an impact on human groups. According to the Health Promotion Model designed by Nola J. Pender (Pender, 1996), life styles change during the life of a person. They are established during childhood and are modified during adolescence, always under a constant interaction between the person and the environment; personal, group and labor interests; together with the stages of this development period.

The LPA as well as the healthy perception of a good practice of physical exercise, avoiding the consumption of tobacco and alcohol, managing stress, practicing good eating habits and personal hygiene are all part of a healthy life style and their practice to guide people to higher levels of $\mathrm{PSOH}$ (Pender, 1996) and as they obtain an appropriate this life style, the levels of SE increase. It is also built through verbal persuasion, which in the case of this work is consolidated in educational interventions in order to successfully form good health behavior beliefs. In theory, manipulating the health cognitive factors could influence the physiological and anthropometric indicators to preserve health through the practice of healthy life styles. Under the premise that LPA currently practiced by adolescents will affect their PSOH in their adult life and their SE levels. In this regard, it is necessary to adapt to new strategies in order to establish the interventions of health care; for example, the use of technologies and social networks in which adolescents spend a large portion of their time, what could be an ideal means to interact with this group and help them to become more responsible or aware of their behavior in order to maintain good health.

Because of the strong influence and accessibility of Internet, we recommend the design of Internet sites controlled by the health services in order to improve the attention given to this predominant group of adolescents (Jiménez et al, 2010). Various authors have carried out interventions using the web aiming to improve behaviors and skills related to the life style of adolescents (Abraham et al, 2015, Chen et al, 2011, Sousa et al, 2015) or through social networks like Facebook (Routsalainen et al, 2015). However, this modality of intervention has been developed in other cultural contexts, at least different from the Latin American environment. Besides, the reports do not specify the creation of a specific program to favor the health cognitive factors in adolescents.

In the face of the published evidence, the objective of this work was the design of a program known as "Health and More" to test the effect of an on-line intervention regarding the health cognitive factors of adolescents from a public school in North Eastern Mexico.

\section{MATERIALS AND METHODS}

Pre-experimental design through a test, re-test model. The population of the study consisted of male and female adolescents between 13 and 15 years of age enrolled in a public high school located in the metropolitan area of Monterrey, Nuevo Leon, Mexico. The sampling was done by convenience since it has to do with an educational center that was already known. However, the selection of each adolescent was done through a simple random sampling making use of the random numbers table starting from a sample list of adolescents who were registered in official lists.
The size of the sample was calculated using the Epi Info ${ }^{\mathrm{TM}}$ 7.1.2.0 software determining a value of $n=250$ adolescents. In order to offer the "Health and More" intervention, it was necessary to hire an information technology and communications expert engineer. It was also necessary to build virtual and simulation spaces. We proceeded first to design the virtual program taking into account interactivity principles, monitoring and innovation.

Together with the aforementioned ideas, we used the Health Promotion Model designed by Nola J. Pender, who states that the adopted behaviors, in this case by adolescents can be explained under three elements of the model. The first or initial one considers personal characteristics and previous experiences, measured by cognitions and affects related to behavior, and ultimately a behavioral result. (Aristizába et al, 2011).

For the purpose of this study, personal factors like age, gender, dedication and educational level were taken from the first construct of the model; the health cognitive factors from Perception of the Health State and the Self-Efficacy concept (defined as the belief to successfully practice certain health behavior) were taken from the second construct. Finally, from the third construct, the expected result determined by the Lifestyle's Perception in Adolescents was evaluated. All these health cognitive factors were evaluated before and after the intervention under a test, re-test model.

The structure of the program used to carry out the intervention was designed in accordance with different research and metaanalysis results that provided evidence of a better direction to manipulate behavioral variables (Abraham et al, 2015; Routsalainen et al, 2015). The contents of the program lasted 8 weeks, dosed and classified in 6 dimensions: 1) responsibility in health, 2) nutrition, 3) physical activity, 4) interpersonal relationships, 5) spiritual growth and, 6) handling of stress. Videos, blogs and interactive messages were loaded onto the program, and connectivity was offered through a link (Experts UANL, 2015) to a health network of experts affiliated to a public university for the purpose of clarifying specific doubts regarding health care.

The application of the instruments was carried out on-line and a link was designed in Survey Monkey. The first things to be investigated were personal factors, including age, gender and place of residence, followed by psychological factors making use of the SF-12 questionnaire (Larson, 2002) designed by the Health Institute, New England Medical Center from Boston Massachusetts. It consists of 12 items with answer options and its score describes a better or worse Perception of the State of Health (PSOH).

The General Scale of Self-Efficacy (SE) was applied (Schwarzer, Baessler, 1996), which consists of 10 items with Likert type of scaling with 4 points each, having from 10 to 40 possible points, classified from very low to low, normal, high and very high self-efficacy. This scale in Spanish has shown high internal consistency (Cronbach's Alpha = 0.87) (Sanjuán et al, 2000).

The LPA of adolescents were measured with the Health Promoting Life Style (HPLS) scale (Walker et al, 1987). Their alpha coefficient has been .943 and the Spanish version has registered internal consistency of .87 (Pérez et al, 2012). 
It consists of 52 items with scores from 1 to 4 , where 1 is never and 4 is always. The score ranges from 52 to 208. The higher score corresponds to a better life style; scores higher than 60 indicate good LPA.

In order to collect the data before and after the intervention, we asked students to come to the computer lab at different times to receive training in the use of the "Health and More" portal. During the time of the intervention, they came to the designated site accompanied by a psychologist who was responsible for the school's mentoring program.

The data were analyzed using the Statistical Package for the Social Sciences (SPSS) version 21 for Windows. The study adhered to the ethical standards of the sponsoring institution. The 14-FaSPyN-SA-31 code was obtained after having been evaluated by the Ethics Committee. The participants signed an informed consent and parents, mentors or representatives also gave their informed consent (Ministry of Health, 1988).

\section{RESULTS}

Sixty percent of the intervention group members were men; $100 \%$ were single men and women; the average age was $13.95 \pm .85$ years. These characteristics created a homogeneous group to carry out the intervention and the experimental group itself was in charge of controlling the process to assess the test, re-test. The questionnaires showed acceptable Cronbach's Alpha, registering values from .71 to .91, and $\mathrm{p}$ values lower than .05 in the Kolmogorov Smirnov test with lilliefors corrections; that is why we opted for non-parametric statistics. From a descriptive point of view, we observed that the test results, when compared with those of the re-test, were different. The HPB, PSOH \& SE indicators increased slightly after the intervention (Table 1).

Table 1 Health cognitive factors in adolescents reported before and after the intervention.

\begin{tabular}{crrrr}
\hline Indicator & \multicolumn{2}{c}{ Before } & \multicolumn{2}{c}{ After } \\
\hline Lifestyle's Perception in & \multicolumn{1}{c}{$f$} & $\%$ & \multicolumn{1}{c}{$f$} & $\%$ \\
Adolescents & 103 & 41.2 & 144 & 57.6 \\
Good & 147 & 51.8 & 106 & 42.4 \\
Bad & & & & \\
Perception of the State of Health & 180 & 2.0 & 215 & 6.0 \\
Good & 70 & 28.0 & 35 & 14.0 \\
Bad & & & & \\
Self-Efficacy & 2 & 0.8 & 0.0 & 0.0 \\
Very low & 31 & 12.4 & 20 & 8.0 \\
Low & 74 & 29.6 & 85 & 34.4 \\
Normal & 113 & 45.2 & 106 & 42.4 \\
High & 30 & 12.0 & 38 & 15.2 \\
Very high & & & & \\
\hline
\end{tabular}

Note: $f=$ Frecuency, $\%=$ Percentaje, $\mathrm{n}=250$

Table 2 Effect of the Intervention on the Health Cognitive Factors of Adolescents

\begin{tabular}{|c|c|c|c|c|c|c|}
\hline \multirow{2}{*}{ Indicator } & \multicolumn{2}{|c|}{ Before } & \multicolumn{2}{|c|}{ After } & \multirow[b]{2}{*}{$z$} & \multirow[b]{2}{*}{$p$} \\
\hline & $M$ & $S D$ & $M$ & $S D$ & & \\
\hline $\begin{array}{c}\text { Lifestyle's } \\
\text { Perception in } \\
\text { Adolescents }\end{array}$ & 47.86 & 15.9 & 54.87 & 14.9 & -13.5 & $.000 *$ \\
\hline $\begin{array}{l}\text { Perception of the } \\
\text { State of Health }\end{array}$ & 64.66 & 9.1 & 74.91 & 15.9 & -11.6 & $.000 *$ \\
\hline Self-Efficacy & 29.28 & 5.0 & 29.46 & 4.7 & -3.2 & $.001 *$ \\
\hline
\end{tabular}

A contrast test was carried out to evaluate the effect using the Wilcoxon Statistics for two related samples in order to have a test, re-test model. The results show a statistical significant effect; the averages of the three variables improved once the intervention was concluded $(\mathrm{p}<.05)$. The results are shown in Table 2.

\section{DISCUSSION}

In the basal measurement, most adolescents indicated that their HPB was bad; more than $25 \%$ evaluated their Perception of their State of Health in the same way. This is interesting because some scientists indicate that young people who think that they have a better State of Health tend to have better Health Promoting Behaviors (Gaete et al, 2014). The objective of this study was to modify said conditions and the results show that there was a significant change by the end of the "Health and More" intervention.

The changes caused by the intervention can be explained through various factors. On the one hand, because we were dealing with adolescents, and taking into account that in this stage of life their curiosity to obtain information from electronic media, where anonymity and confidentiality are two basic elements, a virtual relationship of trust is created between the program's administrator and the person receiving the information. This phenomenon contributes to the adherence to the points, topics and activities proposed in the sessions developed in the intervention (Sanjuán Suarez et al, 2000).

As Pender indicates (Aristizába et al, 2011) life styles and the environment have been identified as the main actors in the high percentage of morbidity and mortality. Nevertheless, small changes in the health system can have an influence in the life styles and contribute to decrease the incidence of some pathology, especially chronic and degenerative pathologies. In this sense, information and communications technologies (IT) can be a good option for the work with adolescents, since they are present in their daily lives and most of them have easy access to said technologies.

The procedures carried out in this work showed accessibility, profitability, anonymity and comfort, characteristics that guided the Interventions based on Internet, which, among other things in their favor, can be available $24 / 7$ and can be accessed anywhere.

On the other hand, the sociodemographic and geographic factors perhaps influenced the results, given that the intervention took place in controlled times, spaces and environments, that is, in the computer lab of the educational institution. In this sense, each participant had the possibility of access to Internet and to be part of the intervention program without the barriers of economic considerations, lack of a computer or internet and were able to adhere to the sessions (Aardoom et al, 2013, Alaoui et al, 2015).

On the other hand, the fact that they feel included in a health program can also have an influence since this population (Portero et al, 2002) does not perceive the existence of a "system" adapted to their characteristics, with adequate tools that attract their attention.

\section{CONCLUSION}

The conclusion is that the intervention via Internet was effective in generating health promoting behaviors in the sample of this study. We recommend a replica of the study increasing the 
methodological rigor taking into account the characteristics of a random clinical Study with control parallel groups.

\section{References}

Aardoom, JJ., Dingemans, AE., Spinhoven, P., Roijen, LA., and Van Furth, EF. (2013). An Internet-based intervention for eating disorders consisting of automated computer-tailored feedback with or without supplemented frequent or infrequent support from a coach: study protocol for a randomized controlled trial. Trials. 14: 340 .

Abraham, A., Chow, WC., So, HK., Yip, BH., Li, AM., Kumta, SM., et al. (2015). Lifestyle Intervention Using an InternetBased Curriculum with Cell Phone Reminders for Obese Chinese Teens: A Randomized Controlled Study. PLoS One. 10 (5): e0125673.

Aristizába Hoyos, GP., Blanco Borjas, DM., Sánchez Ramos, A., and Ostiguín Meléndez, RM. (2011). (Spanish) the Health Promotion Model by Nola Pender. A reflection about her understanding. University Nursing. 8 (4): 16-23.

Chen, JL., Weiss, S., Heyman, MB., Cooper, B., and Lustig, RH. (2011). the efficacy of the web-based childhood obesity prevention program in Chinese American adolescents (Web ABC study). J Adolesc Health. 49 (2): 148-54.

Diaz, KA., Green, DJ., Inqul, CB., Pavey, TG., and Coombes, JS. (2015). Exercise and Vascular Function in Child Obesity: A Meta-Analysis. Pediatrics. 136 (3): 648-59.

El Alaoui, S., Ljótsson, B., Hedman, E., Kaldo, V., Andersson, E., Rück, C., Andersson, G., et al. (2015). Predictors of Symptomatic Change and Adherence in Internet-Based Cognitive Behavior Therapy for Social Anxiety Disorder in Routine Psychiatric Care. PLoS One. 10 (4): 1-18.

Flattum, C., Draxten, M., Horning, M., Fulkerson, JA., Neumark-Sztainer, D., Garwick, A., et al. (2015). HOME Plus: Program design and implementation of a familyfocused, community-based intervention to promote the frequency and healthfulness of family meals, reduce children's sedentary behavior, and prevent obesity. Int J Behav Nutr Phys Act. 12: 53.

Gaete, J., Olivares, E., Rojas-Barahona, CA., Labbé, N., Rengifo, M., Silva, M., Lepe, L., et al. (2014). Factors Associated with Health Promoting Behaviors in Chilean Adolescents. Chilean Medical Magazine. 142 (4): 418-427.

González Ramírez, MT., Landero Hernández, R., and GarcíaCampayo, J. (2009). (Spanish) Relationship between depression, anxiety and psychosomatic symptoms in a sample of university students from the North of Mexico. Panam Public Health Mag. 25 (2): 141-5.

González-Jiménez, E., Montero-Alonso, MA., SchmidtRioValle, J., García-García, CJ., and Padez, C. (2015). Metabolic syndrome in Spanish adolescents and its association with birth weight, breastfeeding duration, maternal smoking, and maternal obesity: a cross-sectional study. European Journal of Nutrition. 54 (4): 589-597.

He, F., Bixler, EO., Liao, J., Berg, A., Imamura Kawasawa, Y., Fernandez-Mendoza, J., et al. (2015). Habitual sleep variability, mediated by nutrition intake, is associated with abdominal obesity in adolescents. Sleep Med. 16 (2): 148994.

Jiménez-Pernett, J., De Labry-Lima, AO., Bermúdez-Tamayo, C., García-Gutiérrez, JF., and Salcedo-Sánchez, M. (2010).
Use of the internet as a source of health information by Spanish adolescents. BMC medical informatics and decision making. 10 (1): 6.

Katzmarzyk, PT., Barreira, TV., Broyles, ST., Champagne, CM., Chaput, JP., Fogelholm M, et al. (2015). Physical Activity, Sedentary Time, and Obesity in an International Sample of Children. Med. Sci. Excerc. 47 (10): 2062-9.

Landgraf, K., Rochstroh, D., Wagner, IV., Weise, S., Tauscher, R., Schwartze, JT., et al. (2015). Evidence of Early Alterations in Adipose Tissue Biology and Function and Its Association with Obesity-Related Inflammation and Insulin Resistance in Children. Diabetes. 64 (4): 1249-61.

Larson, CO. (2002). Use of the SF-12 Instrument for Measuring the Health of Homeless Persons. Health Serv Res. 37 (3): 733-750.

Laurson, KR., Lee, JA., and Eisenmann, JC. (2015). The cumulative impact of physical activity, sleep duration, and television time on adolescent obesity: 2011 Youth Risk Behavior Survey. J. Phys. Act. Health. 12 (3): 355-60.

Ministry of Health. (1988). (Spanish) Regulation of the General Law of Health Regarding Health Research. Available in: www.salud.gob.mx/unidades/cdi/nom/compi/rlgsmis.html

Miqueleiz, E., Te Velde, S., Regidor, E., Van Lippevelde, W., Vik Froydis, N., Fernández-Alvira, JM., et al. (2015). (Spanish) Life habits and care styles of the parents related to childhood obesity: Comparison of a population from Spain with populations from Northern Europe countries: ENERGY-Project. Public Health Spanish Magazine. 89 (5): 523-532.

Mühlig, Y., Antel, J., Föcker, M., and Hebebrand, J. (2016). Are bidirectional associations of obesity and depression already apparent in childhood and adolescence as based on highquality studies? A systematic review, Obes Rev. 17 (3): 235-49.

National Institute of Statistics, Geography and Informatics. (2015)- Statistics Related to the 2015 International Youth Day. National Data [Internet]. Mexico: INEGI. Available in Spanish in: www.inegi.org.mx/saladeprensa/aproposito/ 2015/juventud0.pdf

Pender, NJ. (1996). Health promotion in nursing practice. $3^{\text {rd }}$. Ed. Connecticut: Appleton \& Lange Stanford.

Pérez-Fortis, A., Ulla Diez, SM., and Padilla, JL. (2012). Psychometric properties of the Spanish version of the Health-Promoting Lifestyle Profile II. Res. Nurs. Health. 35 (3): 301-13.

Portero López, P., Cirne Lima, R., and. Mathieu, G. (2002). (Spanish) The intervention with adolescents and young people in the prevention and promotion of health. Spanish Magazine of Public Health. 76 (5): 577-584.

Routsalainen, H., Kyngäs, H., Tammelin, T., Heikkinen, H., and Kääriäinen, M. (2015). Effectiveness of FacebookDelivered Lifestyle Counseling and Physical Activity SelfMonitoring on Physical Activity and Body Mass Index in Overweight and Obese Adolescents: A Randomized Controlled Trial. Nurs Res Pract. 2015: 159205.

Sanjuán Suarez, P., Pérez García, AM., and Bermúdez Moreno, J. (2000). (Spanish) General Self-Efficacy Scale: Psychometric Data of the adaptation for the Spanish population. Psicothema. 12 (2): 509-513. 
Schwarzer, R., and Baessler J. (1996). (Spanish) Evaluation of the Self-Efficacy: Spanish adaptation of the General SelfEfficacy Scale. Anxiety and Stress. 2 (1): 1-8.

Sousa, P., Fonseca, H., Gaspar, P., and Gaspar F. (2015). Controlled trial of an Internet-based intervention for overweight teens (Next.Step): effectiveness analysis, European Journal of Pediatrics. 174 (9): 1143-1157.

Survey Monkey [Internet]. Available in: https://es.survey monkey.com

Ten Hoor, GA., Plasqui, G., Ruiter, RAC., Kremers, SPJ., Rutten, G., Schols, AMWJ., and Kok, GA. (2016). A new direction in psychology and health: Resistance exercise training for obese children and adolescents." Psychol Health. 31 (1): 1-8.
UANL Experts [Internet]. San Nicolas de los Garza, Nuevo León, México, Available in: http://www.expertos.uanl.mx/ (Consulted in 2015).

Walker, K., Sechrist, K., and Pender, NJ. (1987). The healthpromoting lifestyle profile: development and psychometric characteristics. Nursing Research. 36 (2): 76-81.

Walker, SN., Sechrist, KR., and Pender, NJ. (1987). The Health-Promoting Lifestyle Profile: development and psychometric characteristics. Nurs Res. 36 (2): 76-81.

World Health Organization. (2015). (Spanish) Nontransmissible Diseases [Internet]. Available in: http://www.who.int/mediacentre/factsheets/fs355/es/

\section{How to cite this article:}

Guevara-Valtier, MC et al.2017, Intervention Through Internet To Improve Health Cognitive Factors In Adolescents. Int $J$ Recent Sci Res. 8(5), pp. 17128-17132. DOI: http://dx.doi.org/10.24327/ijrsr.2017.0805.0288 